\title{
Quantification of DTI in the Pediatric Spinal Cord: Application to Clinical Evaluation in a Healthy Patient Population
}

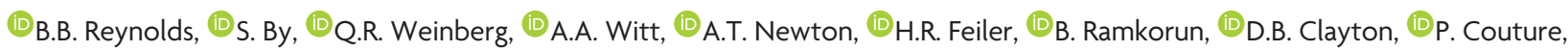

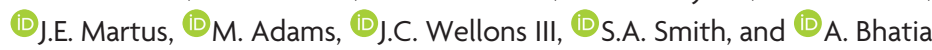

\begin{abstract}
BACKGROUND AND PURPOSE: The purpose of the study is to characterize diffusion tensor imaging indices in the developing spinal cord, evaluating differences based on age and cord region. Describing the progression of DTI indices in the pediatric cord increases our understanding of spinal cord development.
\end{abstract}

MATERIALS AND METHODS: A retrospective analysis was performed on DTI acquired in 121 pediatric patients (mean, 8.6 years; range, 0.3-18.0 years) at Monroe Carell Jr. Children's Hospital at Vanderbilt from 2017 to 2018. Diffusion-weighted images (15 directions; $b=750$ $\mathrm{s} / \mathrm{mm}^{2}$; slice thickness, $5 \mathrm{~mm}$; in-plane resolution, $1.0 \times 1.0 \mathrm{~mm}^{2}$ ) were acquired on a 3T scanner in the cervicothoracic and/or thoracolumbar cord. Manual whole-cord segmentation was performed. Images were masked and further segmented into cervical, upper thoracic, thoracolumbar, and conus regions. Analyses of covariance were performed for each DTI-derived index to investigate how age affects diffusion across cord regions, and $95 \%$ confidence intervals were calculated across age for each derived index and region. Post hoc testing was performed to analyze regional differences.

RESULTS: Analyses of covariance revealed significant correlations of age with axial diffusivity, mean diffusivity, and fractional anisotropy (all, $P<.001$ ). There were also significant differences among cord regions for axial diffusivity, radial diffusivity, mean diffusivity, and fractional anisotropy (all, $P<.001$ ).

CONCLUSIONS: This research demonstrates that diffusion evolves in the pediatric spinal cord during development, dependent on both cord region and the diffusion index of interest. Future research could investigate how diffusion may be affected by common pediatric spinal pathologies.

ABBREVIATIONS: $A D=$ axial diffusivity; $A N C O V A=$ analyses of covariance; $D T I=$ diffusion tensor imaging; $E P I=$ echo planar imaging; $F A=$ fractional anisotropy; $\mathrm{FOV}=$ field-of-view; $\mathrm{GM}=$ gray matter; $\mathrm{MD}=$ mean diffusivity; $\mathrm{PMM}=$ population marginal means; $\mathrm{RD}=$ radial diffusivity; $\mathrm{SNR}=$ signal to noise ratio; $\mathrm{WM}=$ white matter

linical MR imaging of the pediatric spinal cord lacks sensitivity to tissue microstructural abnormalities; however, DTI provides unique information about tissue microstructure and potentially biomarkers for spinal cord pathology through DTI-de-

Received February 13, 2019; accepted after revision May 16

From the Department of Radiology and Radiological Sciences (A.T.N., P.C., S.A.S., A.B.), Urology (D.B.C., M.A.), Pediatrics (A.T.N.), and Division of Pediatric Orthopaedics (J.E.M.), Monroe Carell Jr. Children's Hospital at Vanderbilt, Nashville, Tennessee; Department of Biomedical Engineering (S.A.S.) and Institute of Imaging Science (B.B.R., S.B., Q.R.W., A.A.W., A.T.N., H.R.F., B.R., S.A.S., A.B.), Vanderbilt University, Nashville, Tennessee; Department of Ophthalmology (S.A.S., J.C.W. III), Vanderbilt University Medical Center, Nashville, Tennessee.

This research was supported, in part, by the Surgical Outcomes Center for Kids at Monroe Carell Jr. Children's Hospital at Vanderbilt and through the Section for Surgical Sciences at Vanderbilt University Medical Center.

Please address correspondence to Aashim Bhatia, MD, MS, Monroe Carell Jr. Children's Hospital at Vanderbilt, Department of Radiology, 2200 Children's Way, Suite 1422, Nashville, TN 37232; e-mail: aashimbhatia@gmail.com; @draash

http://dx.doi.org/10.3174/ajnr.A6104 rived indices of axial diffusivity $(\mathrm{AD})$, radial diffusivity $(\mathrm{RD})$, mean diffusivity (MD), and fractional anisotropy (FA) $\cdot{ }^{1-3}$ DTI is relatively well-studied in the brain, including for developmental effects and regional differences, ${ }^{4}$ DTI has aided in the identification and characterization of microstructural discrepancies, which can result from several pathologic mechanisms. ${ }^{5}$

Spinal cord DTI presents additional challenges compared with brain DTI: 1) the small size of the cord; 2) lower SNR; 3) cardiac, respiratory, and patient motion; and 4) dynamic vascular and CSF flow, ${ }^{6}$ all of which are further exacerbated in the pediatric spinal cord. Consequently, spinal cord DTI has been clinically underused, and developmental changes are poorly understood. However, improvements in the optimization of spinal cord DTI offer increased signal to noise, reduced artifacts, and reliability. ${ }^{3,7,8}$ Before pediatric spinal cord DTI can reach its clinical potential, normal ranges of diffusion indices must be established, including the variation in derived indices across development and cord regions. ${ }^{9}$ 
Previous studies in pediatric patients have shown age- and region-related DTI differences and report positive correlations between age and $\mathrm{FA},{ }^{10-12}$ negative correlations between age and $\mathrm{AD},{ }^{11} \mathrm{RD},{ }^{11}$ and $\mathrm{MD},{ }^{10-12}$ and several regional differences. ${ }^{11,12}$ However, these studies used relatively small sample sizes $(n=$ $22-41)^{10-12}$ over an incomplete pediatric age range (6-16 years $)^{11,12}$ and/or used suboptimal DTI sequence parameters. ${ }^{10}$

Our aim was to leverage improved, clinically focused DTI acquisitions in a large clinical sample to characterize the range of normal DTI indices over all pediatric ages and measure variation across age and cord regions in DTI-derived indices. We hypothesized that DTI-derived indices would correlate with age, and the effect of age on DTI indices would differ among spinal cord regions.

\section{MATERIALS AND METHODS \\ Participants}

DTI data were retrospectively collected from 247 pediatric patients (mean age, 7.9 years; range, $0.3-18.0$ years) at Monroe Carell Jr. Children's Hospital at Vanderbilt from 2017 to 2018. All studies were performed under local institutional review board approval (AAA_171784). Only patients with a normal spinal cord (absence of signal abnormalities or pathology in T1- and T2weighted spinal cord images reviewed by a licensed pediatric neuroradiologist) were evaluated and analyzed ( $n=121$; mean age, 8.6 years; range, $0.3-18.0$ years). The indications for the clinical MRIs ranged from back pain to excluding intraspinal pathology.

\section{Data Acquisition}

Imaging was performed using a 3T whole-body MR imaging scanner (Achieva; Philips Healthcare, Best, the Netherlands). A quadrature body coil was used for excitation, and a 16-channel sensitivity encoding neurovascular coil and a 15-channel spine array were used for reception for cervicothoracic and thoracolumbar volumes, respectively. DTI datasets and clinical sequences (sagittal and axial T1- and T2-weighted) were acquired in either the cervicothoracic or thoracolumbar regions or both.

Each DTI acquisition used a reduced-FOV ${ }^{13}$ spin-echo with a single-shot EPI readout in the axial plane. ${ }^{14}$ Scans were acquired with 15 uniformly sampled directions $\left(b=750 \mathrm{~s} / \mathrm{mm}^{2}\right)$ and a minimally weighted image $\left(b=0 \mathrm{~s} / \mathrm{mm}^{2}\right)$ and were cardiac-gated. Additional parameters were the following: anteroposterior phase encoding direction; sensitivity encoding $=1.5$; flip angle $=90^{\circ}$; $\mathrm{TR}=5$ beats $(\sim 5$ seconds $) ; \mathrm{TE}=50 \mathrm{~ms}$; in-plane resolution $=$ $1 \times 1 \mathrm{~mm}^{2}$; slice thickness $=5 \mathrm{~mm} ; 14$ slices; FOV $=64 \times 48 \mathrm{~mm}$; diffusion gradient times of $\Delta=24.4 \mathrm{~ms}$ and $\delta=12.8 \mathrm{~ms}$; and total scan time $=\sim 4$ minutes and 30 seconds. ${ }^{7}$

\section{Data Processing}

The diffusion tensor was estimated with the Camino toolbox (www.camino.org.uk) using a nonlinear fit. ${ }^{15} \mathrm{AD}, \mathrm{RD}, \mathrm{MD}$, and FA maps were calculated from the eigenvalues of the diffusion tensor. Manual segmentation of whole-cord ROIs was performed on the $b=0$ images to maximize cord-containing voxels while minimizing visual partial volume effects of CSF, and ROIs were drawn on AD, RD, MD, and FA maps. Furthermore, for each ROI drawn, we examined the median value to exclude outliers due to
CSF. Images with extensive motion artifacts were not analyzed; however, in many of our younger patients, individuals were scanned under anesthesia, which minimized gross motion. To identify outlier voxels, we calculated the $99.5 \%$ value for each DTI-derived index across all voxels and all patients; voxels in each DTI-derived map greater than the $99.5 \%$ value were removed $\left(\mathrm{AD}_{99.5}=4.432, \mathrm{RD}_{99.5}=1.200, \mathrm{MD}_{99.5}=2.181, \mathrm{FA}_{99.5}=\right.$ 0.999 ).

For each image set, the vertebral locations of the most rostral and caudal cord-containing slices were identified and assigned. Image slices were labeled as cervical if between vertebral levels $\mathrm{C} 1$ and C7, upper thoracic if between $\mathrm{T} 1$ and T6, and as thoracolumbar if at T7 or lower. The last 4 cord-containing slices $(20 \mathrm{~mm})$ of thoracolumbar images identified as the conus were removed from the thoracolumbar set. A single mean value was calculated across all slices for each region in which a patient had data, resulting in 72 cervical, 33 upper thoracic, 100 thoracolumbar, and 107 conus segments of the spinal cord. Figure $1 \mathrm{~A}$ presents an 8 -year-old patient's sagittal T2-weighted image and the corresponding location of diffusion imaging. However, the exact location of imaging volumes varied from patient to patient. Figure $1 B$ shows sample DTI-derived indices for each cord region from the same 8-yearold patient.

\section{Statistical Analysis}

Statistical analyses were performed in Matlab (MathWorks, Natick, Massachusetts). ANCOVA was performed for each DTIderived index using Matlab's Analysis of Covariance Tool, aoctool. Patient age served as the predictor variable; spinal cord region, as the categoric variable; and DTI index, as the dependent variable. Separate regression lines were modeled for each cord region. Eta squared $\left(\eta^{2}\right)$ and partial $\eta^{2}$ were calculated as measures of effect size. ${ }^{16}$ As a model for the "normal" range of diffusion values, pointwise 95\% confidence bands were calculated for each cord region and DTI index. Post hoc comparisons among slope, intercept, and population means were performed with Matlab's multcompare function. The Scheffé procedure was used for multiple-comparison correction. ${ }^{17}$ Statistical significance was identified at $P<.05$.

\section{RESULTS}

\section{Analyses of Covariance}

AD ANCOVA significantly correlated with age $(F=44.26, P<$ $.0001)$ and showed significant differences among cord regions $(F=8.72, P<.0001)$. There was no significant interaction between the age and region $(F=1.36, P=.26)$. Effect size measures, $\eta^{2}$ and partial eta squared $\left(\eta_{p}^{2}\right)$ indicated that age accounted for $11.69 \%-12.71 \%$ of the variance in $\mathrm{AD}\left(\eta^{2}=0.1169, \eta_{p}^{2}=\right.$ $0.1271)$, whereas region accounted for $6.92 \%-7.93 \%$ of the variance $\left(\eta^{2}=0.0692, \eta_{p}^{2}=0.0793\right)$. Figure $2 A,-D$ shows trends for $\mathrm{AD}$ and age across the cervical, upper thoracic, thoracolumbar, and conus regions of the spinal cord.

RD ANCOVA revealed no correlation with age $(F=2.24$, $P=.14)$ but showed significant differences among cord regions $(F=5.43, P=.001)$. There was no significant interaction between age and region $(F=0.94, P=.42)$. Effect size measures indicated that region accounted for $5.01 \%-5.08 \%$ of the variance in $\mathrm{RD}$ 


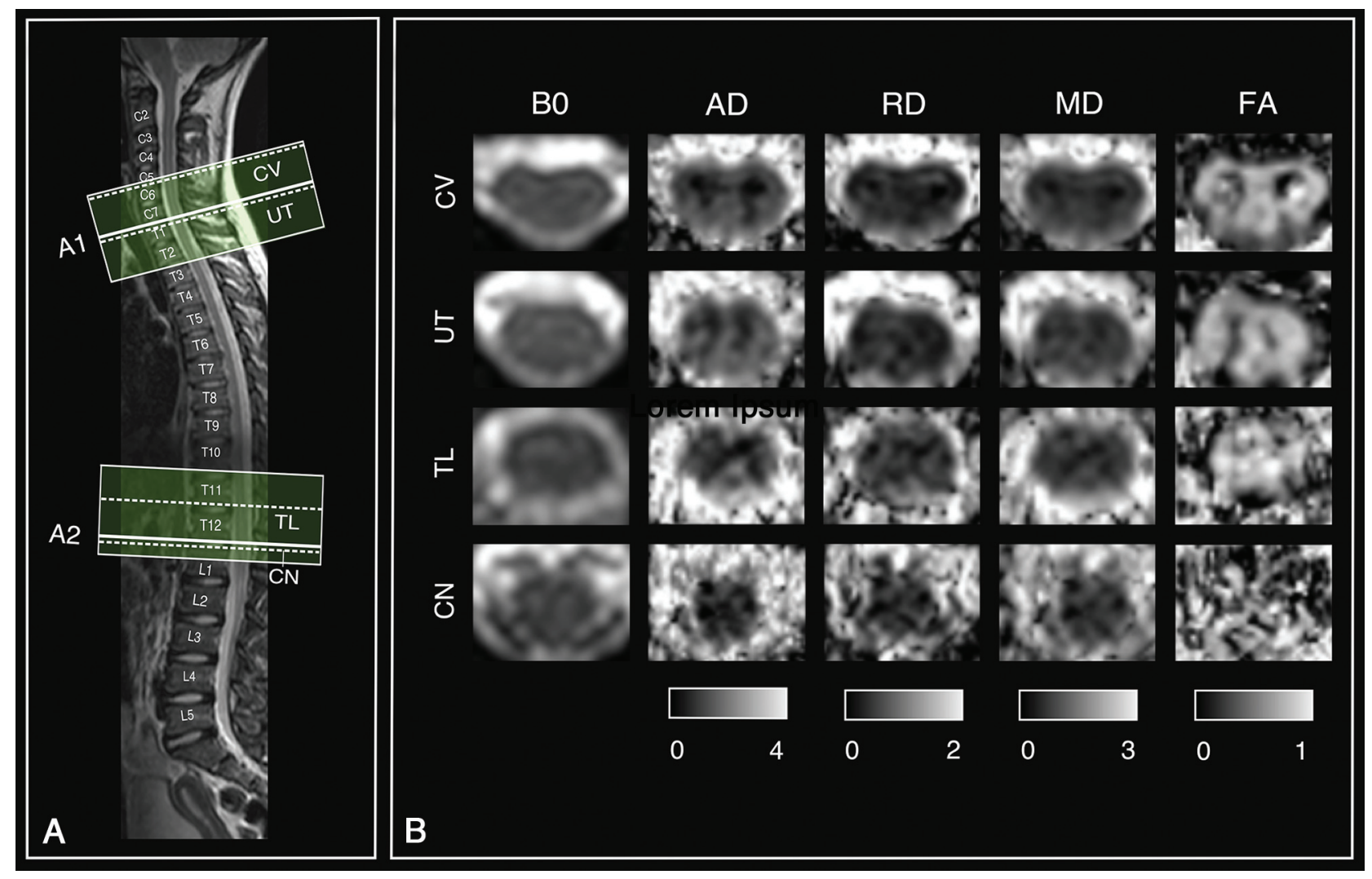

FIG 1. Diffusion images and metrics. A, Patient's sagittal T2-weighted image with overlay shows where 2 different diffusion imaging volumes (Al and A2) were acquired and to which region they were assigned. B, Sample DTI-derived maps for each region for the same patients as in $A$. $B_{0}$ indicates minimally weighted diffusion image; CV, cervical; UT, upper thoracic; TL, thoracolumbar; CN, conus. Scale bars show the range of visualized values for each metric.

values $\left(\eta^{2}=0.0501, \eta_{p}^{2}=0.0508\right)$. Figure $2 E-H$ shows trends for $\mathrm{RD}$ and age across cord regions.

MD ANCOVA significantly correlated with age $(F=16.20$, $P=.001)$ and showed significant differences among cord regions $(F=6.93, P<0.001)$. There was no significant interaction between age and region $(F=1.44, P=.23)$. Effect size measures indicated that age accounted for $4.69 \%-5.06 \%$ of the variance in MD values $\left(\eta^{2}=0.0469, \eta_{p}^{2}=0.0506\right)$, whereas region accounted for $6.02 \%-6.40 \%$ of the variance $\left(\eta^{2}=0.0602, \eta_{p}^{2}=0.0640\right)$. Figure $2 I-L$ shows trends for $\mathrm{MD}$ and age across cord regions.

FA ANCOVA significantly correlated with age $(F=96.11$, $P<.001)$ and showed significant differences among cord regions $(F=6.55, P<0.001)$. There was no significant interaction between age and region $(F=1.94, P=.12)$. Effect size measures indicated that age accounted for $22.58 \%-24.02 \%$ of the variance in MD values $\left(\eta^{2}=0.2258, \eta_{p}^{2}=0.2402\right)$, whereas region accounted for $4.62 \%-6.07 \%$ of the variance $\left(\eta^{2}=0.0462, \eta_{p}^{2}=\right.$ $0.0607)$. Figure $2 M-P$ shows trends for FA and age across cord regions.

ANCOVA summary statistics and $\eta^{2}$ and $\eta_{p}^{2}$ are presented in the Table.

\section{Post Hoc Comparisons}

$\mathrm{AD}, \mathrm{RD}, \mathrm{MD}$, and $\mathrm{FA}$ post hoc testing revealed no significant differences in age-related slope or intercept for cord regions; however, it did show significant differences in population marginal means for region comparisons.

\section{DISCUSSION}

The purpose of the study was to characterize DTI-derived indices across the pediatric spinal cord, evaluating differences in age and cord region, and to expand our understanding of diffusion trends in the normal pediatric cord, potentially benchmarking the clinical utility of DTI. Herein, clinically acquired diffusion MR imaging from 121 patients across the pediatric age spectrum was studied. ANCOVA analyses showed evidence of increasing axial diffusivity, mean diffusivity, and fractional anisotropy in the spinal cord during maturation, with $95 \%$ confidence bands identifying the normal variations across each region and age. Post hoc analyses demonstrated that trends were present throughout the spinal cord, yet average diffusion indices differed among cord regions, with higher diffusivities $(\mathrm{AD}, \mathrm{RD}$, and $\mathrm{MD})$ in rostral compared with caudal regions and lower FA in the thoracolumbar cord.

In the brain, the trajectory of DTI indices of white matter during maturation are well-described and characterized by increasing FA and decreasing diffusivities (AD, RD, and MD), with higher order cognitive regions developing later than lower order sensorimotor regions. ${ }^{18-22} \mathrm{AD}$ exhibits a generally weaker developmental trend and high variability across regions, with $\mathrm{AD}$ decreasing with age in cortical white matter, ${ }^{19,20}$ exhibiting no change in the corticospinal tract ${ }^{19}$ and increasing in the pons. ${ }^{20}$ While our observed age-related trends of increasing $\mathrm{AD}$, $\mathrm{MD}$, and FA do not match developmental trends in brain white 


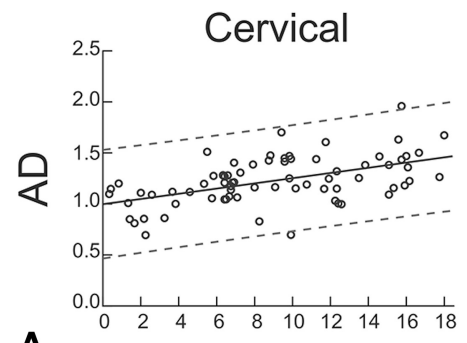

A
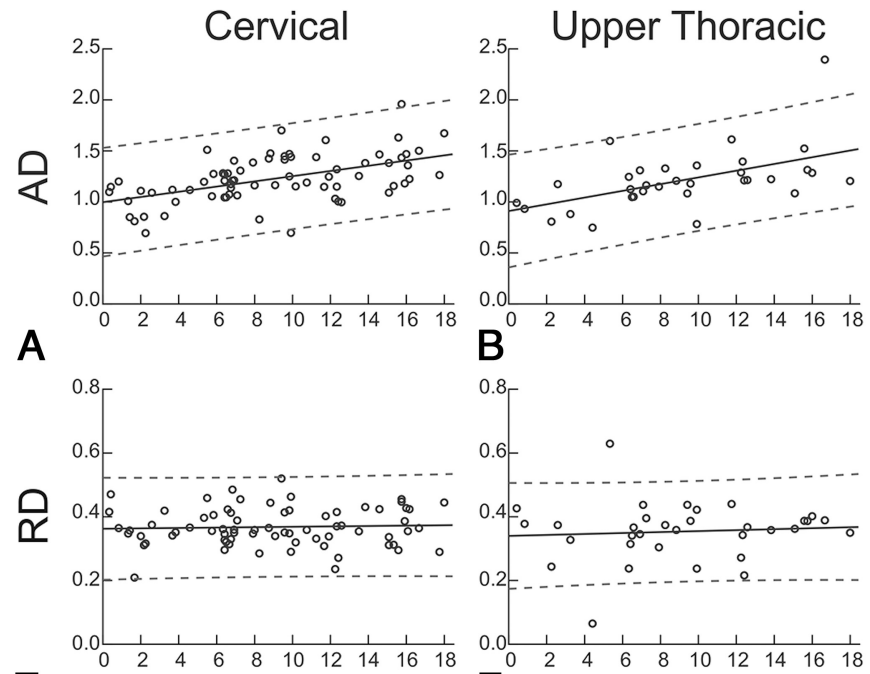

$\mathrm{E}$
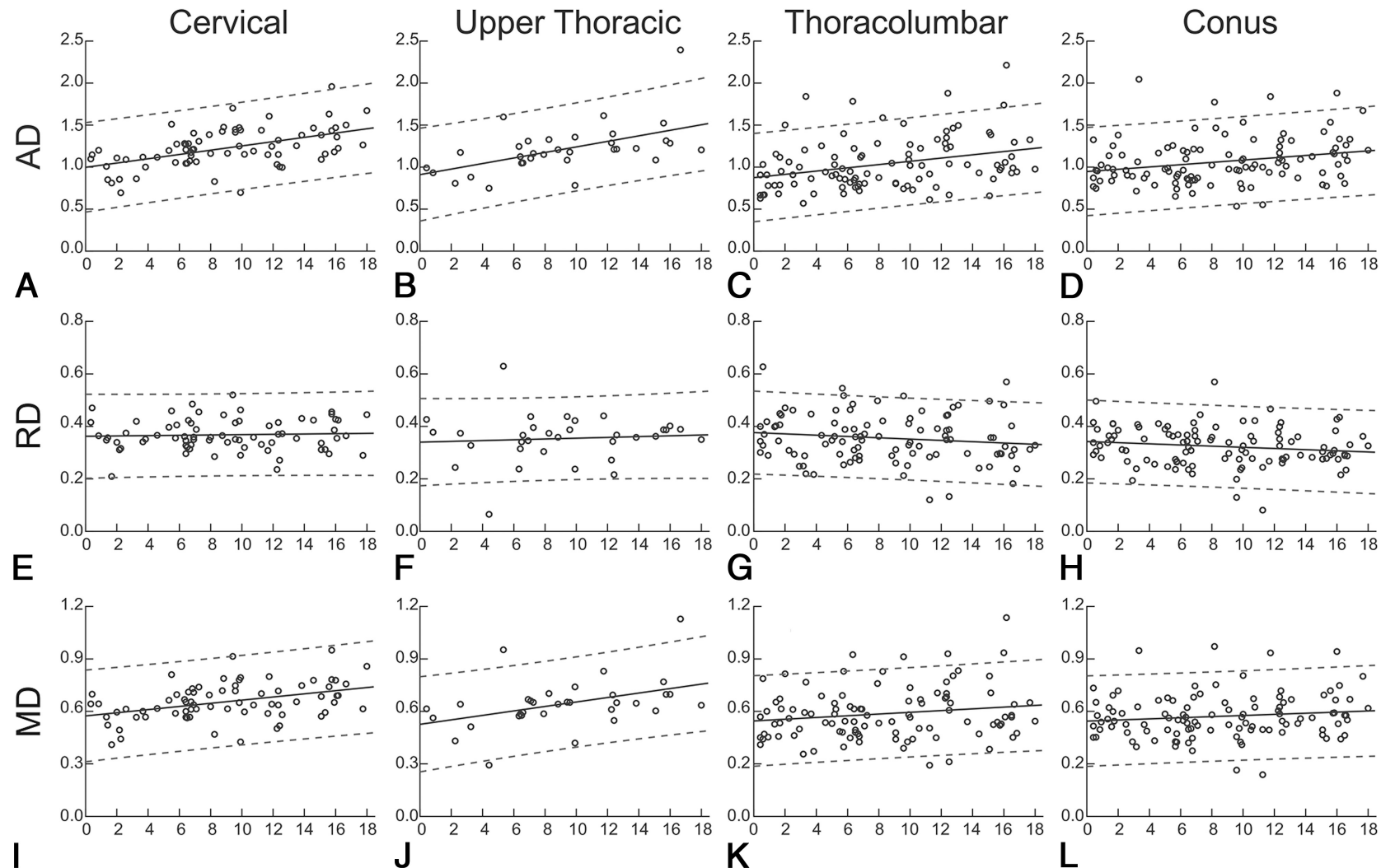

I
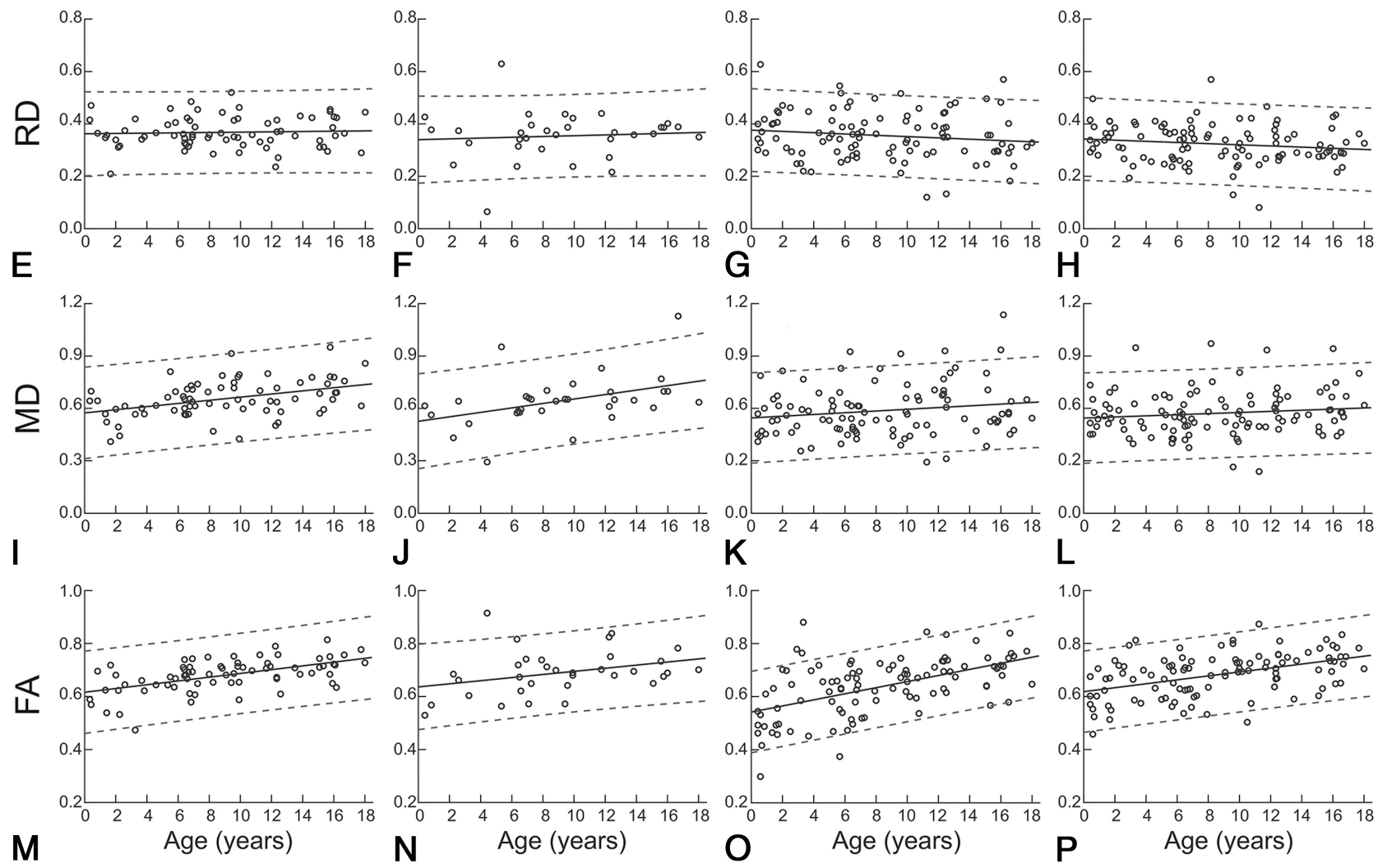

FIG 2. Average regional DTI indices as a function of age. Age-related trends are shown across pediatric development for each spinal cord region and diffusion-derived index. Circles show mean DTI-derived index values for individual patients, solid lines indicate the age-related trend, and dashed lines indicate the $95 \%$ confidence interval.

matter (WM), the spinal cord contains both WM and gray matter (GM), which may exhibit different trends. In the brain, the GM/WM ratio decreases during development. ${ }^{23,24}$ While brain growth progresses rapidly from birth until early childhood, ${ }^{19,25}$ development in childhood and beyond occurs primarily through increasing WM volume and decreasing GM volume. ${ }^{23,24}$ If the spinal cord is myelinated early in infancy, then a decreasing GM/WM ratio could be responsible for increased AD. Although the lack of a significant decrease in RD suggests that a decreasing GM/WM ratio may not be the sole process responsible for our findings, it is also likely that the proportion of larger sized axons (compared with smaller axons) within a voxel increases with the growth of the child and contributes positively to the increasing $\mathrm{AD}$ in the spinal cord with age. Last, it is well-understood that FA and $\mathrm{AD}$ can be biased upward due to low SNR, and the acquisitions we used were optimized for improved speed and concomitantly SNR compared with conventionally acquired DTI of the brain.

Previous pediatric studies comparing DTI-derived indices across age and cord regions have shown positive correlations between age and $\mathrm{FA},{ }^{10-12}$ agreeing with our findings. However, some have reported negative correlations between age and $\mathrm{AD},{ }^{11}$ $\mathrm{RD},{ }^{11}$ and $\mathrm{MD},{ }^{10-12}$ disagreeing with our findings. However, previous studies used the following: 1 ) a narrower age range for subjects $\left.(6-16 \text { years })^{11,12} ; 2\right)$ smaller sample sizes $(n=22-41)^{10-12}$; 3) a non-cardiac-gated DTI acquisition, ${ }^{10-12}$ which reduces robustness $^{26}$; and/or 4) manually defined ROIs. ${ }^{10-12}$ These differences may account for the discrepancies between our results and previous literature.

We hypothesize that some of the regional (across spinal levels) differences in DTI indices could be partly related to an increasing GM/WM ratio of the caudal cord compared with the rostral levels. We also posit that the myelination within the spinal cord is possibly more mature and uniform at birth in a full-term neonate compared with the brain and less of a factor in regional differences.

To our knowledge, this study investigates the largest dataset of pediatric spinal cord DTI to evaluate variations across age and 
ANCOVA and eta statistics

\begin{tabular}{|c|c|c|c|c|c|c|c|}
\hline ANCOVA/Factor & Sum Squared & $d f$ & Mean Squared & $F$ & $P$ Value & $\eta^{2}$ & Partial $\eta^{2}$ \\
\hline \multicolumn{8}{|l|}{ Axial diffusivity } \\
\hline \multicolumn{8}{|l|}{ Main effects } \\
\hline Age & 3.045 & 1 & 3.045 & 44.26 & $<.001$ & 0.1169 & 0.1271 \\
\hline Region & 1.801 & 3 & 0.600 & 8.72 & $<.001$ & 0.0692 & 0.0793 \\
\hline \multicolumn{8}{|l|}{ Interaction } \\
\hline Age $\times$ region & 0.280 & 3 & 0.093 & 1.36 & .26 & 0.0108 & 0.0132 \\
\hline Model error & 20.917 & 304 & 0.069 & & & 0.8032 & \\
\hline Model totals & 26.044 & & & & & & \\
\hline \multicolumn{8}{|l|}{ Radial diffusivity } \\
\hline \multicolumn{8}{|l|}{ Main effects } \\
\hline Age & 0.014 & 1 & 0.014 & 2.24 & .14 & 0.0069 & 0.0073 \\
\hline Region & 0.101 & 3 & 0.034 & 5.43 & .001 & 0.0501 & 0.0508 \\
\hline \multicolumn{8}{|l|}{ Interaction } \\
\hline Age $\times$ region & 0.018 & 3 & 0.006 & 0.94 & .42 & 0.0087 & 0.0092 \\
\hline Model error & 1.890 & 304 & 0.006 & & & 0.9344 & \\
\hline Model totals & 2.023 & & & & & & \\
\hline \multicolumn{8}{|l|}{ Mean diffusivity } \\
\hline \multicolumn{8}{|l|}{ Main effects } \\
\hline Age & 0.270 & 1 & 0.270 & 16.20 & $<.001$ & 0.0469 & 0.0506 \\
\hline Region & 0.346 & 3 & 0.115 & 6.93 & $<.001$ & 0.0602 & 0.0640 \\
\hline \multicolumn{8}{|l|}{ Interaction } \\
\hline Age $\times$ region & 0.072 & 3 & 0.024 & 1.44 & .23 & 0.0125 & 0.0140 \\
\hline Model error & 5.061 & 304 & 0.017 & & & 0.8804 & \\
\hline Model totals & 5.749 & & & & & & \\
\hline \multicolumn{8}{|l|}{ Fractional anisotropy } \\
\hline \multicolumn{8}{|l|}{ Main effects } \\
\hline Age & 0.563 & 1 & 0.563 & 96.11 & $<.001$ & 0.2258 & 0.2402 \\
\hline Region & 0.115 & 3 & 0.038 & 6.55 & $<.001$ & 0.0462 & 0.0607 \\
\hline \multicolumn{8}{|l|}{ Interaction } \\
\hline Age $\times$ region & 0.034 & 3 & 0.011 & 1.94 & .12 & 0.0136 & 0.0187 \\
\hline Model error & 1.781 & 304 & 0.006 & & & 0.7143 & \\
\hline Model totals & 2.493 & & & & & & \\
\hline
\end{tabular}

cord region and represents the most comprehensive coverage of the pediatric age range to date. Also, we further demonstrate the feasibility of acquiring clinical DTI of the pediatric spinal cord with sufficient quality to identify biologically relevant effects. With a greater understanding of the normal variation in pediatric patients, we can leverage these findings to study pathologic processes and increase the clinical use of spinal cord DTI in pediatrics. Damage to spinal cord microstructure in trauma, infection, or congenital spinal dysraphism may result in abnormal DTI-derived indices. ${ }^{27-29}$ Individual pathologies may exhibit distinctive patterns of diffusion changes that could aid in clinical decision-making in combination with clinical signs and symptoms.

There are limitations that should be considered in light of our results. First, the DTIs in this study were collected from pediatric patients who were being evaluated for potential spinal pathology. A licensed pediatric neuroradiologist reviewed T1- and T2weighted images for each patient to identify patients with a normal-appearing spinal cord, but it is possible that pathology was not detected by conventional imaging in some patients. Second, DTI indices were obtained within a whole-cord ROI, including both GM and WM. With the GM/WM ratio varying across age and cord regions, ${ }^{30,31}$ the change in the GM/WM ratio could contribute to the effects seen. Third, DTI of the pediatric spinal cord is a low-SNR acquisition (small imaging region, motion artifact, and CSF flow), and a low SNR results in bias toward higher FA values but not diffusivities. ${ }^{32}$ The conus is the small- est volume of cord tissue in this analysis, and with the decreased cord size, fewer voxels are contained in the ROIs placed. While this region did demonstrate similar trends of age-related changes in the DTI indices, further studies with improved DTI protocols need to be evaluated in a larger sample size. Last, manually selected whole-cord masks are standard practice in spinal cord DTI analysis ${ }^{10-12}$ due to the limited resolution of clinically feasible acquisitions, yet they can introduce subjectivity into the analysis and may reduce reproducibility. ${ }^{33}$

Progress is being made on the development of objective and automated segmentation of the spinal cord, including differentiation between GM and WM. ${ }^{34}$ Future work will be focused on confirming these results in age-matched controls. We are currently in the process of differentiating the DTI indices across both GM and WM throughout the spinal cord using high-resolution sequences with increased SNR, such as multiecho fast-field gradient echo, a Philips proprietary sequence, which will be coregistered with the DTI acquisition.

\section{CONCLUSIONS}

We demonstrate that microstructure-sensitive DTI-derived indices evolve in the pediatric spinal cord during development and depend on both the DTI index of interest and cord region. Future research will investigate whether GM and WM follow these trends exclusively and whether DTI in the pediatric spinal cord could serve as a clinical biomarker for spinal pathologies. 
Disclosures: Samantha By—UNRELATED: Employment: Hyperfine, Philips, Comments: employee of Hyperfine August 27, 2018 to present, employee of Philips, August 2018 to September 2019; Stock/Stock Options: Hyperfine.

\section{REFERENCES}

1. Hasan KM, Walimuni IS, Abid H, et al. A review of diffusion tensor magnetic resonance imaging computational methods and software tools. Comput Biol Med 2011;41:1062-72 CrossRef Medline

2. Le Bihan D, Mangin JF, Poupon C, et al. Diffusion tensor imaging: concepts and applications. J Magn Reson Imaging 2001;13:534-46 CrossRef Medline

3. Martin AR, De Leener BD, Cohen-Adad J, et al. Clinically feasible microstructural MRI to quantify cervical spinal cord tissue injury using DTI, MT, and T2*-weighted imaging: assessment of normative data and reliability. AJNR Am J Neuroradiol 2017;38:1257-65 CrossRef Medline

4. Oishi K, Faria AV, Yoshida S, et al. Quantitative evaluation of brain development using anatomical MRI and diffusion tensor imaging. Int J Dev Neurosci 2013;31:512-24 CrossRef Medline

5. Carney O, Falzon A, MacKinnon AD. Diffusion-weighted MRI in paediatric neuroimaging. Clin Radiol 2018;73:999-1013 CrossRef Medline

6. Clark CA, Hedehus M, Moseley ME. In vivo mapping of the fast and slow diffusion tensors in human brain. Magn Reson Med 2002;47: 623-28 CrossRef Medline

7. By S, Smith AK, Dethrage LM, et al. Quantifying the impact of underlying measurement error on cervical spinal cord diffusion tensor imaging at 3T: error in cervical spinal cord DTI at 3T. J Magn Reson Imaging 2016;44:1608-18 CrossRef Medline

8. Smith SA, Jones CK, Gifford A, et al. Reproducibility of tract-specific magnetization transfer and diffusion tensor imaging in the cervical spinal cord at 3 Tesla. NMR Biomed 2010;23:207-17 CrossRef Medline

9. Taso M, Girard OM, Duhamel G, et al. Tract-specific and age-related variations of the spinal cord microstructure: a multi-parametric MRI study using diffusion tensor imaging (DTI) and inhomogeneous magnetization transfer (ihMT). NMR Biomed 2016;29: 817-32 CrossRef Medline

10. Singhi S, Tekes A, Thurnher M, et al. Diffusion tensor imaging of the maturing paediatric cervical spinal cord: from the neonate to the young adult. J Neuroradiol 2012;39:142-48 CrossRef Medline

11. Saksena S, Middleton DM, Krisa L, et al. Diffusion tensor imaging of the normal cervical and thoracic pediatric spinal cord. AJNR Am J Neuroradiol 2016;37:2150-57 CrossRef Medline

12. Alizadeh M, Fisher J, Saksena S, et al. Age related diffusion and tractography changes in typically developing pediatric cervical and thoracic spinal cord. Neuroimage Clin 2018;18:784-92 CrossRef Medline

13. Wilm BJ, Svensson J, Henning A, et al. Reduced field-of-view MRI using outer volume suppression for spinal cord diffusion imaging. Magn Reson Med 2007;57:625-30 CrossRef Medline

14. Wheeler-Kingshott CA, Hickman SJ, Parker GJ, et al. Investigating cervical spinal cord structure using axial diffusion tensor imaging. Neuroimage 2002;16:93-102 CrossRef Medline

15. Cook PA, Bai Y, Nedjati-Gilani S, et al. Camino: Open-Source Diffusion-MRI Reconstruction and Processing. In: Proceedings of the Annual Meeting of the International Society for Magnetic Resonance in Medicine, Seattle, Washington. May 6-12, 2006;14:1

16. Cohen J. Eta-squared and partial eta-squared in fixed factor ANOVA designs. Educational and Psychological Measurement 1973; 33:107-12 CrossRef
17. Hochberg Y, Tamhane AC. Multiple Comparison Procedures. New York: Wiley; 1987

18. Engelbrecht V, Scherer A, Rassek M, et al. Diffusion-weighted MR imaging in the brain in children: findings in the normal brain and in the brain with white matter diseases. Radiology 2002;222:410-18 CrossRef Medline

19. Faria AV, Zhang J, Oishi K, et al. Atlas-based analysis of neurodevelopment from infancy to adulthood using diffusion tensor imaging and applications for automated abnormality detection. Neuroimage 2010;52:415-28 CrossRef Medline

20. Löbel U, Sedlacik J, Güllmar D, et al. Diffusion tensor imaging: the normal evolution of ADC, RA, FA, and eigenvalues studied in multiple anatomical regions of the brain. Neuroradiology 2009;51: 253-63 CrossRef Medline

21. Yoshida S, Oishi K, Faria AV, et al. Diffusion tensor imaging of normal brain development. Pediatr Radiol 2013;43:15-27 CrossRef Medline

22. Qiu A, Mori S, Miller MI. Diffusion tensor imaging for understanding brain development in early life. Annu Rev Psychol 2015;66: 853-76 CrossRef Medline

23. Courchesne E, Chisum HJ, Townsend J, et al. Normal brain development and aging: quantitative analysis at in vivo MR imaging in healthy volunteers. Radiology 2000;216:672-82 CrossRef Medline

24. Paus T, Collins DL, Evans AC, et al. Maturation of white matter in the human brain: a review of magnetic resonance studies. Brain Res Bull 2001;54:255-66 CrossRef Medline

25. Dekaban AS, Sadowsky D. Changes in brain weights during the span of human life: relation of brain weights to body heights and body weights. Ann Neurol 1978;4:345-56 CrossRef Medline

26. Figley CR, Stroman PW. Investigation of human cervical and upper thoracic spinal cord motion: implications for imaging spinal cord structure and function. Magn Reson Med 2007;58:185-89 CrossRef Medline

27. Grabher P, Mohammadi S, Trachsler A, et al. Voxel-based analysis of grey and white matter degeneration in cervical spondylotic myelopathy. Sci Rep 2016;6:24636 CrossRef Medline

28. Rajasekaran S, Yerramshetty JS, Chittode VS, et al. The assessment of neuronal status in normal and cervical spondylotic myelopathy using diffusion tensor imaging. Spine 2014;39:1183-89 CrossRef Medline

29. Cui JL, Li X, Chan TY, et al. Quantitative assessment of columnspecific degeneration in cervical spondylotic myelopathy based on diffusion tensor tractography. Eur Spine J 2015;24:41-47 CrossRef Medline

30. Junghanns H, Schmorl G. The Human Spine in Health and Disease. Philadelphia: Grune \& Stratton; 1971

31. Fontana PA, Barbeito CG, Goya RG, et al. Impact of very old age on the expression of cervical spinal cord cell markers in rats. $J$ Chem Neuroanat 2009;37:98-104 CrossRef Medline

32. Farrell JAD, Landman BA, Jones CK, et al. Effects of signal-to-noise ratio on the accuracy and reproducibility of diffusion tensor imaging-derived fractional anisotropy, mean diffusivity, and principal eigenvector measurements at 1.5T. J Magn Reson Imaging 2007; 26:756-67 CrossRef Medline

33. Barakat $\mathrm{N}$, Shah $\mathrm{P}$, Faro $\mathrm{SH}$, et al. Inter- and intra-rater reliability of diffusion tensor imaging parameters in the normal pediatric spinal cord. World J Radiol 2015;7:279-85 CrossRef Medline

34. Prados F, Ashburner J, Blaiotta C, et al. Spinal cord grey matter segmentation challenge. Neuroimage 2017;152:312-29 CrossRef Medline 